\title{
Improvement Quality of LMS Through Application of Social Networking Sites
}

\author{
http://dx.doi.org/10.3991/ijet.v8i3.2669 \\ Khader Musbah titi ${ }^{1}$, AbdulHafeez Muhammad 1,2 \\ ${ }^{1}$ King Khalid University ,Abha, Kingdom of Saudi Arabia. \\ ${ }^{2}$ Kulliya of ICT, International Islamic University (IIUM) KL, Malaysia.
}

\begin{abstract}
The rapid development of information technology (IT), especially in education, influences all educational institutions to adopt eLearning. E-learning as a primary means of instruction is expanding significantly at the college and university level. However, most of these colleges and universities tend to emphasize on its benefits only. This does not mean that eLearning is without deficiencies. Students' interactions, attention and communications are relatively low in the current Learning Management Systems (LMS). LMS is missing the direct relation between learning content and students' collaboration and in an inappropriate educators approach towards eLearning. Additionally, collaboration among learners themselves in real time is not supported by LMS. Simultaneously, the growth of social networking sites (SNS) including Facebook, twitter and others are also rising among today's college students. The main aim of this research is to propose a comprehensive model for eLearning, which might be a roadmap for educational institutions over the whole world to adopt. The focus of this new model will be on incorporation and integration of social networking platform (SNP) with LMS to overcome some of the limitations of LMS in order to improve the quality of educational process to make it much better, attractive and more cooperative.
\end{abstract}

Index Terms-E-learning, Learning Management Systems (LMS), Social Networking platform (SNP)

\section{INTRODUCTION}

E Learning is rapidly developing, supported by growing sophistication of information technology (IT) and by better understanding of how to make content and delivery of e-courses more effective using sophisticated Learning Management System (LMS). E learning has now been moved into a new generation that concenters on more learner engagement and social learning and provides learners with collaborative and learner-centered online learning environments [1].

The use of LMS provides learners and educators with a set of tools for improving the learning processes and managing them [2]. LMS is a set of standardized tools for learning, which are designed to integrate learning with the existing information systems within an organization or through the web portal for learning. Moodle learning management system is one of the most frequently used open source products that is flexible and adaptable to users and is designed to help educators to create quality online courses [3].

Sharing of information and the improvement of knowledge exchange among learners can be completed by using the concepts of interaction, collaborative learning, and compilation of learners' knowledge [4]. Learning in the context of social media has become highly selfmotivated, independent, and informal, as well as an integral part of the college experience [5].

There is much confirmations that social networks site is increasingly supporting informal learning at home and in community and that informal learning is becoming a vital element of education for learners of all ages [6].

The main aim of this research is to improve the quality of the educational process by using Facebook applications integrated with the current LMS. From learners' aspect, the objectives of this application are to motivate learners to learn through it and to test their knowledge from specific online course in such way that is more interesting than traditional one. Moreover, to enhance the interactions and direct communications of learners with each other. On the other hand, this application brings many benefits to educators. They can use these Facebook applications for tracking learners' progress through tests, publishing courses materials in an attractive form, and for improving communication with learners and with educators themselves. In the remaining part of the paper, we will highlight the concepts LMS, SNS and Web2 respectively in general then will integrate them to propose our model. Finally the conclusion will be given at the end.

\section{LEARNing MANAGEMENT SySTEM}

Learning management systems (LMS) also sometimes known as Course management systems (CMS) have come a long way since those early days. LMS is a broad term used to describe software tools designed to manage user learning interventions and provide access to online learning services for students, teacher, and administrator. LMS is a software application used for administration, documentation, tracking, and reporting of training curriculums, course room and online events, eLearning programs, and training content. As described in [7], a good LMS should be able to perform the following activities:

- use self-service and self-guided services

- assemble and deliver learning content rapidly

- consolidate training initiatives on a scalable webbased platform

- support portability and standards

- Personalize contents and enable knowledge reuse.

- Registration and charging

- Managing the process

- Testing

- Mentoring and monitoring 
- User's function

- Administrator functions

LMSs range from systems for managing training and educational curriculums, to software for delivering courses through the Internet with features for online collaboration [7]. Corporate training uses LMSs to automate record-keeping and employee registration.

Todays, a vast variety of LMS occur, where most of them mainly correspond to all general requests of elearning, like content management, assessments management, users and groups management and tracking of students' progress. LMS completely support the standalone e-learning process based on content feeding and basically support the interaction among users. Learning through collaboration and sharing resources among users in real time is mostly not properly supported in the current LMSs. Today, LMS missing the direct relation between learning content and students' collaboration and in an inappropriate teachers' interactions and approach towards elearning. The next generation of LMS packages, that this research proposed, must be supported of create virtual classrooms where teachers and students' collaboration, communications and social activities will be totally correlated.

\section{SOCIAL NETWORK PlATFORM (SNP)}

Social networking service is an Internet platform, or site that emphases on enabling the constructing of social networks among people for sharing many types of resources such as interests, activities, backgrounds, or real-life connections. SNP provide means for users to interact over the Internet, such as e-mail, chatting and immediate messaging. SNP allow users to share ideas, documents, activities, events, and interests within their individual web site pages.

The main types of social networking services are those that contain category places (such as former school year or classmates), means to connect with friends and a recommendation system linked to trust.

Educators and advocates of new digital literacy are assured that social networking inspires the development of transferable, technical, and social skills of value in formal and informal learning [8]. Tweeting, instant messaging, or blogging enhances student involvement. Students who would not normally participate in traditional class or in the current LMS are more suitable to share through social network services. Networking allows participants the opportunity for just-in-time learning and higher levels of engagement [9]. The use of SNPs allow educators to enhance the suggested curriculum. When learning experiences are infused into a website, students utilize every day for fun, students realize that learning can and should be a part of everyday life. It does not have to be separate and unattached [10]. Informal learning consists of the learner setting the goals and objectives.

In the previous versions of SNP, it was viewed as an entertainment and offered no educational benefit at all. Blocking and filtering these SNP was a form of protection for students against wasting time. In an educational setting, Facebook, for example, is seen by many instructors and educators as a time-wasting distraction from schoolwork, and it is not uncommon to be banned in junior high or high school computer labs [10].
Schools and universities have the option of educating safe media usage as well as incorporating digital media into the classroom experience, thus preparing students for the literacy they will encounter in the future.

But simply, social networking is a way for one person to meet up with other people on the net. People use social networking sites for meeting new friends, finding old friends, or locating people who have the same problems or interests they have, called niche networking. According to ComScore, up to end of November 2011, the number of people who participates in the SNS exceeds one billion registered users (see table 1) [11]:

TABLE I.

NUMBER OF SNP USERS AROUND THE WORLD, [11]

\begin{tabular}{|l|l|}
\hline \multicolumn{1}{|c|}{ Worldwide SNS } & \multicolumn{1}{c|}{ \# of Users } \\
\hline Facebook.com & $792,999,000$ \\
\hline Twitter.com & $167,903,000$ \\
\hline LinkedIn.com & $94,823,000$ \\
\hline Google+ & $66,756,000$ \\
\hline MySpace & $61,037,000$ \\
\hline Others & $255,539,000$ \\
\hline
\end{tabular}

IV. WEB 2.0

The increasing and rapidly development of web 2.0 and Social Network Platform (SNP) technologies have shifted the way people communicate, work, learn and teach [12]. Today's educators are faced with new challenges to involve learners in their courses and to create strategies for effective and high quality learning [13]. The use of SNP in the educational process has taken the attention of both educators and researchers, since they have been widely adopted under student population and offer many functions that could help increase student involvement, attention and communications.

The Web 2.0 was a backbone in the development of gorgeous and innovative web systems in terms of interactivity, enabling the rise of the so-called social software (e.g., social networks, wikis, and social bookmarking). Social software is regularly cited as determinant of transformations that are moving the way people relate to digital technology [14]. The word famous social networks sites such as Facebook, Twitter and YouTube are all examples of how information and communication technology (ICT) has pervaded every aspect of people's personal and social natural life. This kind of new technology is used not only at home, but also in workplaces, public and private organizations, and schools for several dedications, via different tools and with far-reaching consequences.

Web 2.0 is not considered only a technology, but an attitude and social revolution which enables and inspires learners to participate in a socially open environment with rights of content creation, edition and sharing [15]. Five extensive features of Web 2.0 were identified [16]. First, Web 2.0 is a platform that allows users to access and use via Internet. Second, it has a user- friendly and interactive interface. Third, its design encourages users to participate and publish ideas in it. Forth, a social networking tool enables users to provide feedback and exchange ideas collaboratively. Finally, users have content ownerships in the site and rights to control over them. In other words, Web 2.0 denotes ideas of learner- centered, collaborative and interactive learning [15]. 


\section{THE Proposed MOdel}

New information and communication technologies have become major resources and basis for learning in higher education. Technologies have several potentials to support different instructional strategies and provide an efficient way of delivering electronic course material and improving comprehension. Using eLearning in the educational institutions brings many benefits for educational institution, educators and learners. Students can have their learning any time, any place and with less effort and cost. Additionally, social networks platform such as Facebook also has many benefits for educational process. Facebook is very efficient in sharing information with other, efficient in participating in social activities and maintain existing relationships and so on. The advantages of LMS and Facebook can be show in figure 1 .

However, the current LMS has many limitations that make the educational process less effective and produce less skilled professional and less supporters for the society. (See figure 2).

The current LMS are helpful software for management of learners and content for e-learning. Creation Content and distribution is well managed in most of the current LMS, however learners and educators' interaction and option of active participation of them in the eLearning process is not. Instead there are social networks sites with good support for interaction between users and creation of communities without any support for eLearning. These social tools can be integrated with LMS that can improve the eLearning process [17]. This integrations can be completed through open application programmable interfaces (API), which need to be supported at the SNP and at LMS. As LMS have a good support for learners' progress tracking a hybrid system must support tracking of learners' collaboration. This way learners' collaboration can be considered to be a part of learners' final success, forcing users (students) to collaborate actively by increasing theirs' motivation (see figure 3).

Facebook social network has been selected due to its best support for third party controls and numerous active users. The SNP is going to be used as a backend for social tools and LMS is also going to be used as a backend for elearning components.

Integration process of a LMS to a SNP only can be done when social networking platform supports third party controls to be added for custom users. Thus, a new interface of an existing LMS with a look and feel of the selected SNP must be created. At the end of the integration process all of the social tools available in the platform could be totally used.

The proposed model shown in figure. 3.0 illustrates the common architecture of the application, where the application will be used to provide an interface between the application and Facebook. Facebook Platform is the tools that accommodate those functionalities. As can be seen from figure 3.0, this platform contains three elements Facebook API, FBML, FBJavascript and FQL. Detail of each elements can be found in Facebook's Developers page [18]. Facebook API is stand for application programming interface (API), it is a protocol intended to be used as an interface by software components to communicate with each other. It is a set of software libraries that enables developers to work with an application without knowing anything about its internal workings. So, by

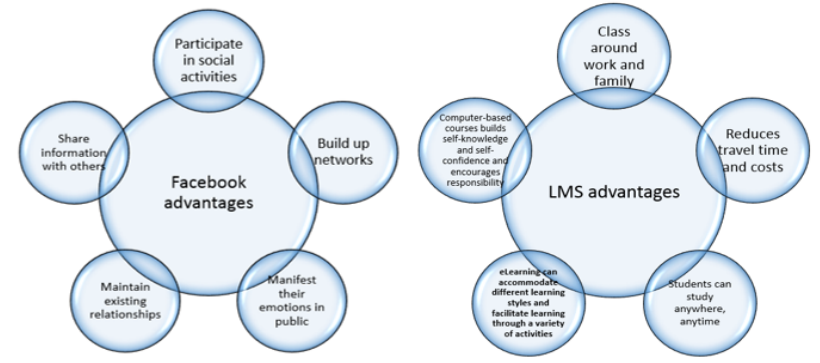

Figure 1. advantages of LMS and Facebook

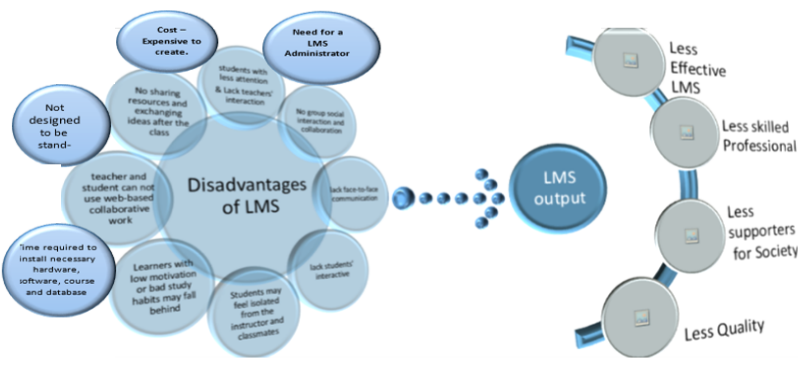

Figure 2. disadvantages of the current LMS and its result

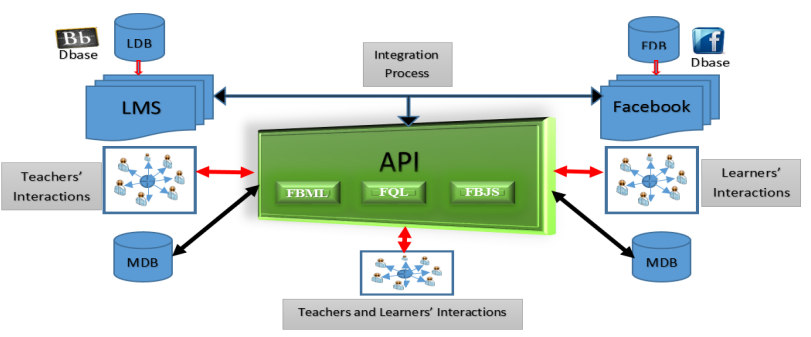

Figure 3. Integration LMS with Facebook through API

using Facebook API, anyone can develop any Facebook applications easily and unlimitedly with only required skills in web programming.

FBML stands for Facebook markup language page and it is used to enhance and optimize web site pages. It has the same rule and structure as common HTML (Hypertext Markup Language), only additional tags related to Facebook features.

FQL stand for Facebook Query Language, it is refer to the information that is stored in Facebook's database. To be able to reach the database, the only way is to use FQL. It is similar to previously known SQL (Structured Query Language) for managing and maintain database.

FBML does not support the use of standard JavaScript using the script element. However, Facebook JavaScript (FBJS) allows for limited scripting functionality inside a Facebook application.

From the point of view of Facebook and LMS, there are differences but there are also facts that enhancing each other. From the transparency and share-ability of Facebook and the unlimited distance and highly interactive learning of LMS, the integration of an LMS to Facebook will enhance each purpose. Facebook will no longer be used only for entertainment, it will be educational and LMS will be as acceptable as it built inside Facebook. Managing courses in this new integrated system is an easy process, students activities is more transparent since every activity in virtual course is shared as their status, new learning material is as easy as tag-share feature in Facebook, and more other features. 


\section{CONCLUSION}

In this paper, we proposed a new model to make all elearning process more efficient and more reliable. Social networking tools that could improve the interaction among users in e-learning environments are being considered as a possible solution to increase attention and interaction among users. An integration of learning management system with a social networking platform is being proposed with an interesting model for e-learning. This can help instructors to design courses more effectively, detect anomalies, inspire and direct further research.

\section{REFERENCES}

[1] Nicholson, P.A (2007). History of e-learning: echoes of the pioneers. In Fernández- Manjyn, B., et al. (Eds.), Computers and education: e-learning, from theory to practice (pp. 1-11). Netherland: Springer.

[2] García-Peñalvo, F.J., Conde, M.A., Alier, M. \& Casany, M.J. (2011). Opening Learning Management Systems to Personal Learning Environments. Journal of Universal Computer Science. 17 (9), 1222-1240. DOI: 10.3217/jucs-017-09-1222.

[3] Cole, J. \& Foster, H. (2007). Using Moodle: Teaching with the Popular Open Source Course Management System., 2 ed. California: O'Reilly.

[4] Cole, J. \& Foster, H. (2007). Using Moodle: Teaching with the Popular Open Source Course Management System., 2 ed. California: O'Reilly.

[5] McGloughlin, C. \& Lee, M.J.W. (2010). Personalised and self regulated learning in the Web 2.0 era: International exemplars of innovative pedagogy using social software. Australasian Journal of Educational Technology, 26(1), 28-43. ISSN: 14493098

[6] Kitsantas, A. \& Dabbagh, N. (2010). Learning to learn with Integrative Learning Technologies (ILT): A practical guide for academic success. Information Age Publishing, Greenwich.

[7] Ellis, Ryann K, Field Guide to Learning Management System. 2009.

[8] Livingstone, Sonia; Brake, David R. (2010). "On the Rapid Rise of Social Networking Sites: New Findings and Policy Implications". Children \& Society 24 (1): 75-83. http://dx.doi.org/ 10.1111/j.1099-0860.2009.00243.x Retrieved July 16, 2012.

[9] Lou, Tian; Gao, Fei (2012). "Enhancing Classroom Learning Experience by Providing Structures to Microblogging Based Activities". Journal of Information Technical Education 11.

[10] Gardner, J. Clark. "Facebooks Potential in the Classroom". http://www.jclarkgardner.com/uploads/5/4/1/4/5414483/jclark_gar dner_facebook_classroom.pdf

[11] "ComScore: Google+ Grows Worldwide Users From 65 Million In October To 67 Million In November". December 22, 2011.
[12] Kaplan, A. M., \& Haenlein, M. (2010). Users of the world, unite! The challenges and opportunities of Social Media. Business Horizons, 53(1), 59-68 http://dx.doi.org/10.1016/j.bushor.2009.09.003

[13] Greenhow, C., Robelia, B., \& Hughes, J. E. (2009). Learning, teaching, and scholarship in a digital age: Web 2.0 and classroom research: What path should we take now? Educational Researcher, 38(4), 46-259. http://dx.doi.org/10.3102/0013189X09336671

[14] Greenhow, C., Robelia, B., \& Hughes, J. E. (2009). Learning, teaching, and scholarship in a digital age: Web 2.0 and classroom research: What path should we take now? Educational Researcher, 38(4), 46-259. http://dx.doi.org/10.3102/0013189X09336671

[15] Yau, J., Lam, J. \& Cheung, K.S. (2009). A Review of e-Learning Platforms in the Age of e-Learning 2.0. In Wang, F.L., Fong, J., Zhang, L. \& Lee V.S.K. (Eds.), Hybrid

[16] Duffy, P. (2008). Using YouTube: Strategies for using new media in teaching and learning. In Kwan, R., Fox, R., Chan, F.T., Tsang, P. (eds.), Enhancing learning through technology: research on emerging technologies and pedagogies (pp. 31-44). Singapore: World Scientific Publishing Co. Pre. Ltd. http://dx.doi.org/ 10.1142/9789812799456 0003

[17] Social Media Tools For Learning, http://theelearningcoach.com/ elearning2-0/10-social-media-tools-for-learning/, last update: 2011, visited: 1. December 2011.

[18] Hayder, Hasin and Dr Bain, Alexander Mark, Learning Facebook Application Development. Pack Publishing : Birmingham. 2008

\section{AUTHORS}

Dr Khader Musbah titi is working as an Assistant Professor in Information System Department of Computer Science, College of Computer Science, King Khalid University, Abha, Kingdom of Saudi Arabia. He is graduated Masters Degree from University of Sunderland and Doctorate from Arab Academic for Business and Financial Sciences His research Interest includes Security, elearning, Cyberspace, e-commerce and Quality (email: drkhadermuspah@gmail.com)

AbdulHafeez Muhammad is working as lecturer in Department of Computer Sc Department of Computer Science, College of Computer Science, King Khalid University, Abha, Kingdom of Saudi Arabia since last 6 years. He is graduated MS in Software Engineering form International Islamic University Islamabad, Pakistan. He is also pursuing his $\mathrm{PhD}$ (IT) from International Islamic University Malaysia. His research area is ethical perspective in Virtual Learning Environment and Education Management through ICTs. This work is carried out as part of his area of research interest and higher studies. (email: abdulhafeez97@gmail.com) 